\title{
Editorial: Forensic engineering UK
}

Costas Georgopoulos CEng, FHEA, FCS, FIStructE, FICE Chair and Honorary Editor, Editorial Advisory Panel and Professor, Department of Civil Engineering, Kingston University, London, UK

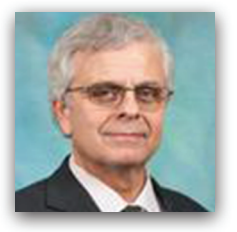

As this is the fifth anniversary of the journal I would like to start this editorial by thanking the members of the Editorial Advisory Panel, the paper reviewers and the publisher's staff for their contribution to the journal's success in achieving an excellent international reputation and standing. The journal's impact factor has quickly risen from 0 to 0.24 in four years - that is remarkably close to the impact factor of old, established journals such as Civil Engineering In these first few years of its life, the journal has published 20 issues with 79 papers and 21 briefings on professional practice and original research in forensic engineering and developed a healthy waiting list of promising authors and potential papers. Themed issues have been instrumental in delivering the forensic engineering message and include themes on education, tunnels and resilience to climate change as well as the currently developing themes of structural health monitoring, forensic engineering in developing countries and urban renovation. I would like first briefly to introduce the papers in this issue and then take this opportunity to examine the past and look at the future of the journal and forensic engineering UK as a whole.

This issue includes two papers and one briefing with three different messages, clearly demonstrating the diverse nature of forensic engineering. The first paper, by Chou (2016), is about deterioration assessment of ageing immersed-tube road tunnels in Taiwan. Cracks, water ingress and corrosion are usually the threats and nondestructive inspection techniques are normally used to determine the level of deterioration and to make an overall assessment of the tunnel's operational safety. The second paper, by Tanikawa (2016), is an example of lessons learned from disaster response after the Great East Japan Earthquake. Securing traffic on major routes connecting affected areas after an earthquake is of paramount importance. In this case, measures such as the use of rest areas as disaster response bases, introducing inspection procedures in the early stages after the disaster and strengthening cooperation with related organisations are instrumental in improving the disaster-resistance of expressways. The briefing by Smith (2016) is an example of the well-established contribution of forensic engineering to standards. In this case, faulty utilities roadworks caused cracking to a house that was not supposed to happen as the peak particle velocity did not appear high enough to meet the critical damage levels in accordance with BS 7385 (BSI, 1993). Further investigation revealed that the standard equipment measuring short pulses was wrong and that BS 7385 statements on permissible short pulses are based on these wrong values, enabling utility companies to escape liability for damage. Time for BS 7385 to be corrected.

Back in 2010, I wrote, 'Twenty-first century engineers, driven by sustainability and technology, are pushing science to new limits by creating leaner structures with modern materials using stateof-the-art design and novel construction techniques. They operate in a changing global climate of increased intensity natural hazards and manmade disasters. Managing and mitigating higher risks may be considered a challenge in engineering new structures and also a threat in assessing the vulnerability of existing infrastructure, especially in the underdeveloped world; a timely launch of Forensic Engineering' (Georgopoulos, 2011: p. 1).

Five years later in 2015, I can quote what the president of the Institution of Civil Engineers (ICE) wrote in the foreword of the Forensic Engineering themed issue on defining hazards from climate change for resilient design, that we 'must be [able] to accurately answer the question "what if?" Understanding what happens when extreme weather events occur, particularly the cascading effects of failing infrastructure, will enable us to be better prepared. It will also enable us to develop more flexible and adaptive response measures, both structural and non-structural' (Balmforth, 2015: p. 45).

Forensic engineering underpins our understanding and learning from failures that has traditionally been an integral part of professional practice, research and education of civil engineers. However, forensic engineering in the UK is currently at its infancy. Our universities do not provide the necessary forensic engineering skills to our graduates. The Forensic Engineering journal has pointed this out with its education themed issue (Mottram and Smith, 2012). The Joint Board of Moderators, the degree accreditation body funded by ICE and other professional engineering institutions, specifically says 'the engineering profession has lacked an emphasis on feedback and learning; it is imperative that we get our young engineers to understand the importance to learn from failure' (JBM, 2009: p. 2). It is about time that every civil engineering graduate has acquired forensic engineering skills. It is about time that we create a body that becomes a recognised authority on forensic engineering and supports our industry to really learn from failures and near misses by raising standards and preventing and/or mitigating future damages. At the last editorial panel meeting, the idea of creating a 'Forensic Engineering Forum' was unanimously approved.

\section{REFERENCES}

Balmforth D (2015) Foreword. Proceedings of the Institution of Civil Engineers - Forensic Engineering 168(2): 45, http://dx.doi.org/10.1680/feng.2015.168.2.45.

BSI (1993) BS 7385-2 Part 2:1993: Evaluation and measurement for vibration in buildings. Guide 
to damage levels from groundborne vibration. BSI, London, UK.

Chou YC (2016) Deterioration assessment of an immersedtube road tunnel in Taiwan. Proceedings of the Institution of Civil Engineers - Forensic Engineering 169(1): 6-13, http://dx.doi.org/10.1680/jfoen.13.00028.

Georgopoulos C (2011) Editorial. Proceedings of the Institution of Civil Engineers - Forensic Engineering 164(1): 1-2, http://dx.doi.org/10.1680/feng.2011.164.1.1.

JBM (Joint Board of Moderators) (2009) Degree Guidelines Annex F Professionalism. JBM, London, UK.
Mottram T and Smith K (2012) Editorial. Proceedings of the Institution of Civil Engineers - Forensic Engineering 165(3): 109-110, http://dx.doi.org/10.1680/feng.12.00014.

Smith JD (2016) Shocks cause trouble with BS 7385.

Proceedings of the Institution of Civil Engineers Forensic Engineering 169(1): 3-5, http://dx.doi.org/10.1680/jfoen.15.00011.

Tanikawa T (2016) Lessons learned from the Great East Japan Earthquake. Proceedings of the Institution of Civil Engineers - Forensic Engineering 169(1): 14-24, http://dx.doi.org/10.1680/jfoen.14.00019. 